\title{
Influence of moderate electric fields in $\beta$-lactoglobulin thermal unfolding and interactions
}

\author{
Rui M. Rodrigues ${ }^{\mathrm{a}, *}$, Zita Avelar ${ }^{\mathrm{a}}$, António A. Vicente $^{\mathrm{a}}$, Steffen B. Petersen ${ }^{\mathrm{b}}$, Ricardo N. Pereira ${ }^{\mathrm{a}}$ \\ ${ }^{\text {a }}$ CEB - Centre of Biological Engineering, University of Minho, Campus de Gualtar, P-4710-057 Braga, Portugal \\ ${ }^{\mathrm{b}}$ Medical Photonics Lab, Department of Health Science and Technology, Faculty of Medicine, Aalborg University, Fredrik Bajers vej 7, DK-9220 Aalborg, Denmark
}

\section{A R T I C L E I N F O}

\section{Keywords:}

$\beta$-Lactoglobulin

Moderate electric fields

Thermal denaturation

Proteins structure

Protein interactions

\begin{abstract}
A B S T R A C T
In this study, the effects of moderate electric fields during thermal denaturation of $\beta$-lactoglobulin were examined through an in situ circular dichroism approach, complemented by intrinsic extrinsic fluorescence analysis. Results have shown that the effects of electric fields in protein unfolding were linearly dependent on the applied electric field intensity $(\mathrm{V} / \mathrm{cm})$ and increased by the use of low electric frequencies - i.e. 50 to $200 \mathrm{~Hz}$. These electric effects caused significant changes on $\beta$-lactoglobulin melting temperature, unfolded conformation and subsequent intermolecular interactions, revealed by the increase of surface hydrophobicity (ANS affinity) and higher conservation of retinol binding. The obtained data provides a clear evidence that moderate electric fields contribute to distinct folding/unfolding of $\beta$-lactoglobulin, resulting in structural modifications. These findings are relevant for (bio)-technological applications involving electric fields processing, bringing new insights for the development of innovative strategies to control protein function and tune production of functional protein systems.
\end{abstract}

\section{Introduction}

Beta-lactoglobulin ( $\beta-\lg )$ is a well-studied protein, considered as a model for globular protein interactions, unfolding and aggregation (Creamer, Loveday, \& Sawyer, 2011; Kontopidis, Holt, \& Sawyer, 2004). In addition to its scientific relevance, $\beta-\lg$ has significant industrial and technological importance (Nicolai, Britten, \& Schmitt, 2011; Ramos et al., 2015). Under physiological conditions $\beta$-lg exists on a monomer-dimer equilibrium, with predominance of the dimeric form (Mercadante et al., 2012). Nevertheless this equilibrium is pH dependent and can also be shifted by controlling the environmental conditions such as protein concentration and ionic strength (Wang, Allen, \& Swaisgood, 1998). $\beta$-lg's secondary structure is composed by $15 \%$ of $\alpha$ helices, $50 \%$ of $\beta$-strands and about $20 \%$ of reverse turns. It has a core structure formed by a $\beta$-barrel, creating a hydrophobic cavity which is capable of establishing several interactions, namely the binding of small hydrophobic molecules (Khorsand Ahmadi, Mahmoodian Moghadam, Mokaberi, Reza Saberi, \& Chamani, 2015; Kontopidis, Holt, \& Sawyer, 2002). A particular affinity to retinol has been documented, with an apparent association constant similar to that of plasma retinol-binding protein, with which it shares homology (Kontopidis et al., 2002; Papiz et al., 1986).

$\beta$-lg's thermal denaturation is complex, with a sequence of modifications in its tertiary and secondary structures that do not take place simultaneously, but somewhat successively or triggering each other (Cairoli, Iametti, \& Bonomi, 1994; Loveday, 2016; Tolkach \& Kulozik, 2007). Early stages of tertiary structure modifications, at around $60{ }^{\circ} \mathrm{C}$, result in exposure of a free cysteine and may lead to disulphide aggregation (Iametti, De Gregori, Vecchio, \& Bonomi, 1996). Close to physiological conditions (near neutral $\mathrm{pH}$ and low ionic strength), the middle point of $\beta$-lg's thermal transition $\left(T_{m}\right)$ is around $74^{\circ} \mathrm{C}$. However, due to differences in thermal stability of different domains, this protein can present different denaturation levels below and above $T_{m}$, with higher or lower preservation of its structural features (Fessas, Iametti, Schiraldi, \& Bonomi, 2001; Tolkach \& Kulozik, 2007). In fact, $\beta$-lg retains a significant fraction of its native structure even at temperatures of $90^{\circ} \mathrm{C}$, existing in partially unfolded states, consistent with the molten globule model (Bhattacharyya \& Varadarajan, 2013; Qi et al., 1997). In these partially unfolded forms, the protein presents thiol reactivity, increased tryptophan (Trp) exposure and accessible hydrophobic patches (Bhattacharjee \& Das, 2000; Cairoli et al., 1994). The structural rearrangements and increased interaction potential resulting from the protein's partial denaturation are often the basis for the development of new protein functionalities (Bryant \& McClements, 1998; Nicolai et al., 2011).

The influence of an external electric field (EF) on protein structure

\footnotetext{
* Corresponding author.

E-mail address: ruirodrigues@ceb.uminho.pt (R.M. Rodrigues).
} 
and stability has been the subject of several studies with different approaches. Most of the literature available on the effects of EF makes use of high voltage $(\geq \mathrm{kV})$ applications for short periods of exposure ( $\mu$ s and ns). These conditions are consistent with the ones used in pulsed electric field (PEF) technology or considered in in silico approaches through molecular dynamic simulations (English \& Waldron, 2015; Zhao, Yang, \& Zhang, 2012). EF effects in whey proteins, and particularly in $\beta-\mathrm{lg}$, have been demonstrated under PEF treatments where tertiary and secondary structure modifications were observed under voltage gradients above $12 \mathrm{kV} / \mathrm{cm}$ (Perez \& Pilosof, 2004; Xiang, Ngadi, OchoaMartinez, \& Simpson, 2011; Yang et al., 2018). Another application of EF technology is the use of EF of low intensity, relative to PEF, known as moderate electric fields (MEF). MEF specifications comprise EF values between 1 and $1000 \mathrm{~V} / \mathrm{cm}$, with variable frequencies and wave shape, usually considering unrestricted treatment times, that can range from a few seconds to minutes or even hours (Rocha et al., 2018; Sastry, 2008). Several examples of applications operating under such electric field specifications include ohmic heating, electro filtration, dielectric separation, among others (Geada et al., 2018; Rocha et al., 2018). Several authors have investigated MEF action in protein structure and activity, either by experimental studies or by conjugation of experimental results with dynamic molecular simulations. MEF effects on protein conformation and activity was shown at non-denaturing temperatures, even at low voltage gradients (Bekard \& Dunstan, 2014; Samaranayake \& Sastry, 2016b, 2018). It was hypothesized that the presence of a MEF induces molecular motions resultant from the oscillatory behaviour of the electric field applied. These motions are particularly effective at low electrical frequencies $(<100 \mathrm{~Hz})$ resulting in local energy dissipation, yielding as an apparent elevation of temperature on the protein molecules. Significant work has also been developed on the conjugation of thermal and electrical effects in protein systems (Pereira, Souza, Cerqueira, Teixeira, \& Vicente, 2010; Pereira, Teixeira, \& Vicente, 2011; Rodrigues et al., 2015), focusing on complex systems (i.e. WPI) and the impact in functional aspects such as aggregation and gelation. In a recent study the use of ohmic heating, and the inherent presence of MEF, on pure fractions of $\beta$-lg demonstrated to significantly affect protein's structural features like conformation, surface hydrophobicity and thiol reactivity (Rodrigues, Vicente, Petersen, \& Pereira, 2019). Nevertheless, there is a lack of fundamental knowledge regarding the effects caused by MEF and its variables in protein structural transitions and intermolecular interactions - i.e. protein binding properties.

In this study, we assessed the influence of MEF and its variables (i.e. electric field strength and frequency) during $\beta$-lg thermal unfolding. In order to do so an in situ approach with thermal scan circular dichroism (CD) was used, which allowed following the changes in structural features imposed by thermal and electrical effects during MEF's treatments. Far-UV CD spectra analysis and fluorescence spectroscopy of the endogenous tryptophan were used to assess changes in structural features imposed by MEF; ligand binding studies with ANS and retinol were also performed aiming at demonstrating differentiated binding affinities, possibly resulting from altered conformations imposed by the treatments applied.

\section{Materials and methods}

\subsection{Protein solutions}

$\beta$-lg was purified from commercial whey protein isolate (Lacprodan DI-9212, Arla Foods, Viby, Denmark) using the salting out method adapted from Maté and Krochta (1994) and Konrad, Lieske and Faber (2000). This method is effective in recovering high purity fractions of $\beta$ $\mathrm{lg}$, and particularly recovering it in its native form. The recovery yield was of $25 \%$ of the estimated total amount of $\beta-1 g$ in the isolate; the remaining protein (denatured and aggregated fractions) was discarded during the purification process. The final product was freeze-dried and stored a $-20^{\circ} \mathrm{C}$ until use. Purified proteins were compared to commercial $\beta$-lg from Sigma-Aldrich (lyophilized powder $\geq 90 \%$ PAGE) and against literature reports, using HPLC, Native and SDS-PAGE, as well as circular dichroism (CD), matching it in all criteria, thus ensuring purity and conformation.

$\beta-\lg$ solutions, $10 \mu \mathrm{M}$, were prepared in sodium phosphate buffer $(25 \mathrm{mM})$ at $\mathrm{pH}$ 7.0. The solutions were stirred until full solubilisation and, if needed, the $\mathrm{pH}$ was adjusted with $1 \mathrm{M}$ hydrochloric acid or sodium hydroxide.

\subsection{Structural changes upon thermo-electric treatments}

CD spectra were collected on a Jasco J-1500 CD spectrophotometer (Jasco Inc., Tokyo, Japan) between 250 and $190 \mathrm{~nm}$ at $20^{\circ} \mathrm{C}$, using a $1 \mathrm{~mm}$ quartz cuvette. Experimental parameters were as follows: band width, $1 \mathrm{~nm}$; data pitch, $1 \mathrm{~nm}$; scanning speed, $50 \mathrm{~nm} / \mathrm{min}$; response D.I.T. $1 \mathrm{~s}$; accumulations, 5; the CD spectrum of the blank was subtracted from each recorded spectra. In order to determine the fractions of secondary structure elements on the protein $\mathrm{CD}$ spectra analysis was performed using DICHROWEB software (Whitmore \& Wallace, 2008). The analysis program CONTIN was used with the reference set 4, optimized for the wavelength interval of $190-240 \mathrm{~nm}$.

For CD thermal shift assay, samples were placed into $1 \mathrm{~mm}$ pathlength quartz cell equipped with a custom-built system with two platinum electrodes embedded on the cuvette cap. The electrodes fit the sidewalls of the cuvette in all its length with a constant electrode gap of $0.9 \mathrm{~cm}$. The cell was placed on the thermostated holder and temperature was monitored with a thermocouple placed inside the cuvette. $\mathrm{CD}$ spectra were collected in $5{ }^{\circ} \mathrm{C}$ increments, at a heating rate of $1{ }^{\circ} \mathrm{C} / \mathrm{min}$ over the temperature range of 20 to $95^{\circ} \mathrm{C}$. After the target temperature was reached, the temperature was brought back to $20^{\circ} \mathrm{C}$ and the spectra of the unfolded/partially refolded protein were collected. During the process, an electric field was applied through the voltage output of a function generator $(1 \mathrm{~Hz}-25 \mathrm{MHz}$ and 1 to $10 \mathrm{~V}$; Agilent $33220 \mathrm{~A}$, Penang, Malaysia). For the control samples, similar setups were used, without the presence of the electric field. Finally, the samples were collected and used for further analysis.

Given the inclusion low frequencies in this study, additional precautions were taken to minimize possible electrochemical reactions such as water electrolysis, electrode oxidation and erosion. These problems were minimized through the use of a low power system, thus preventing excessive energy dissipation, and through the use of platinum as electrode material (Rieger, 1994). The platinum stability and corrosion resistance minimizes electrode oxidation and sample contamination. A visual inspection was performed before and after each test, confirming the absence of bubbling, electrode erosion or other signs of electrochemical reactions. For higher frequencies (i.e. $>17$ $\mathrm{kHz}$ ) the electrochemical phenomena are virtually inexistent (Pataro et al., 2014; Samaranayake, Sastry, \& Zhang, 2005).

\subsection{Fluorescence determinations}

Fluorescence determinations were conducted using the fluorescence instrument Aqualog (Horiba-Jobin Yvon, Inc. Japan). Intrinsic fluorescence was determined exciting Trp present in the protein at $295 \mathrm{~nm}$ and collecting the emission from 300 to $450 \mathrm{~nm}$. 8-Anilino-1-naphthalenesulfonic acid (ANS) from Sigma-Aldrich was used as hydrophobic fluorescent probe, in order to determine the accessibility of the protein's hydrophobic sites. ANS solution was prepared in methanol at $1.5 \mathrm{mM}$ and stored at $4{ }^{\circ} \mathrm{C}$, protected from light. For the assay, ANS stock solution was added to the protein solution to a final concentration of $75 \mu \mathrm{M}$ and allowed to stabilise for $30 \mathrm{~min}$ at room temperature. ANSprotein complex fluorescence was exited at $370 \mathrm{~nm}$ and the emission spectra collected from 400 to $650 \mathrm{~nm}$. 


\subsection{Quenching experiments}

Retinol (all-trans-Retinol, 95\%, ACROS Organics) solution was prepared in absolute ethanol ( $\geq 99.8 \%$, AnalaR NORMAPUR ${ }^{\circledast}$ ACS) at $0.4 \mathrm{mM}$ and used immediately. The retinol solution was titrated manually into the cell using a micro-injector, followed by Trp excitation at $295 \mathrm{~nm}$ and the resulting fluorescence spectra were recorded. For the quenching analysis, absorption correction of the fluorescence values was conducted through the inner filter effect method (Keppler, Stuhldreier, Temps, \& Schwarz, 2014; van de Weert, 2010).

\subsection{Data processing, fitting and analyses}

OriginPro 9.0 was used for all data analyses. All spectra presented is the result of at least three accumulations of independent determinations, smoothed using a 10 points adjacent averaging. For CD spectra analysis to obtain secondary structure quantifications, CD transition profile analysis to estimate the melting temperature $\left(T_{m}\right)$ and for fluorescence quenching experiments, all fitting and calculations were performed individually for each spectroscopic determination and the results are presented as average values with standard deviations.

\section{Results and discussion}

The rates of change in the secondary structure of a protein as a function of temperature can be followed by Far-UV CD spectra (Greenfield, 2007). Fig. 1 shows the changes in $\beta$-lg's CD spectra with the progressive increase of temperature, reflecting the protein structural changes. $\mathrm{CD}$ spectra changes are mostly detected in the region between 190 and $215 \mathrm{~nm}$, were the $\theta$ values become progressively more negative and the spectra minimum shifts towards $204 \mathrm{~nm}$. These changes are consistent with loss of $\beta$-sheets and increase of random coil fractions.

\subsection{MEF effect in $\beta$-lg thermal induced transition}

In order to determine the effects induced by MEF during the thermal unfolding of $\beta-1 g$, variables such as electric frequency, EF strength (V/ $\mathrm{cm}$ ) and wave shape (i.e. sine and square wave) were tested during preliminary experiments. The variation of the EF frequency and strength resulted in observable changes while the use of different wave shapes (sine and square wave) revealed no differences in the thermal unfolding behaviour of $\beta$-lg (results not shown). In this study, results

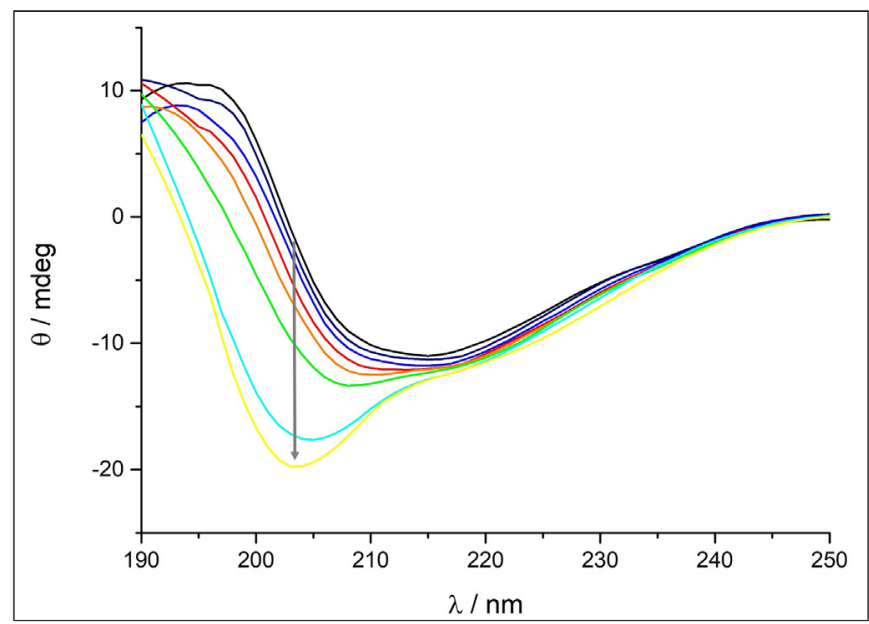

Fig. 1. Far-UV CD spectra $\beta$-lg as function of temperatures. The black line represents the native protein at $20^{\circ} \mathrm{C}$ and the coloured lines spectra collected at $10{ }^{\circ} \mathrm{C}$ increments until $90^{\circ} \mathrm{C}$ (the arrow indicates the change of the magnitude of $\theta$ values at $204 \mathrm{~nm}$ as temperature is increased). refer only to experiments conducted using sine wave MEF.

Following the $\theta$ values at $204 \mathrm{~nm}\left(\theta_{204 \mathrm{~nm}}\right)$ it is possible to track the unfolding transition of the protein's secondary structure, assessing protein stability as a function of temperature and MEF applied. Fig. $2 \mathrm{~A}$ shows the unfolding profiles of $\beta$-lg exposed to different MEF frequencies. The control sample presented a lower initial change rate and higher values of $\theta_{204 \mathrm{~nm}}$ after the transition, when compared with all MEF treated samples. The most contrasting example of MEF effects was the transition profile produced at $50 \mathrm{~Hz}$, where the decrease in $\theta_{204}$ was more pronounced on the initial stages of heating and with a more uniform slope. This suggests that the transition started sooner and was more progressive than the control, until reaching a similar final $\theta_{204}$ value. For the other MEF conditions tested the increasing frequency seems to produce a transition profile more analogous to the control, but with a higher initial rate of change and reaching lower ellipticity levels.

Considering a two state unfolding mechanism, $T_{m}$ was estimated by fitting a Boltzmann sigmoidal curve (Orwig \& Lieberman, 2011). Fig. 2B shows $T_{m}$ values as a function of the frequency applied. $T_{m}$ for the control samples was determined to be $73.15 \pm 1.07^{\circ} \mathrm{C}$, while for samples exposed to MEF, $T_{m}$ values ranged from $51.21 \pm 1.71{ }^{\circ} \mathrm{C}$ at $50 \mathrm{~Hz}$ to $75.23 \pm 1.15^{\circ} \mathrm{C}$ at $1 \mathrm{MHz}$. The very significant decrease of $T_{m}$ caused by exposure to lower MEF frequencies (i.e. 50 and $200 \mathrm{~Hz}$ ) contrasts with a slight increase caused by the higher frequencies $(200 \mathrm{kHz}$ and $1 \mathrm{MHz}$ ), whereas the intermediate frequencies present similar $T_{m}$ values to the control samples. EF effects in $T_{m}$ have been reported in $\beta$-lg exposed to PEF at $12.5 \mathrm{kV} / \mathrm{cm}$ through DCS analysis, demonstrating a decrease of $T_{m}$ up to $5{ }^{\circ} \mathrm{C}$ (Perez \& Pilosof, 2004). In this study, even though conducted with a different electric methodology - i.e. much lower EF strengths, longer treatment times and an assigned electrical frequency - the observed decrease in $T_{m}$ was $>20^{\circ} \mathrm{C}$. This was probably related with the longer exposure times and with the higher temperatures (PEF are a so-called "non-thermal" technology, thus temperature increases are seldom relevant). Nonetheless, the contributions of the EF to a facilitated unfolding transition are evident in both studies.

Previous studies of MEF action upon properties (i.e. conformational changes and enzymatic activity) of various proteins demonstrate a higher influence when low frequencies are applied (Bekard \& Dunstan, 2014; Samaranayake \& Sastry, 2016a, 2016b, 2018). These observations are in line with our experimental data (where for the first time, thermal stability of $\beta$-lg under MEF was analysed): at lower frequencies, a decrease in $T_{m}$ is clearly visible. Therefore, it can be concluded that at low frequencies, the presence of MEF can impose more substantial changes in $\beta$-lg's transition, whereas at high frequencies $T_{m}$ remains practically unchanged although different structural features can be obtained. This will be more evident when looking at data of the secondary structure analysis (see Table 1).

Another relevant aspect of the MEF effects is the influence of the EF strength applied. A similar procedure to the one used to assess the frequency effects was adopted, changing MEF strength $(\mathrm{V} / \mathrm{cm})$ at a fixed frequency (i.e. $50 \mathrm{~Hz}$ ). Fig. $2 \mathrm{C}$ presents the transition profiles and $T_{m}$ variation as a function of EF strength. An increased action of the MEF with the EF strength applied was observed, resulting in a linear decrease of $T_{m}$, thus an early unfolding transition. The linear nature of this decrease suggests a proportional action between the EF applied and the destabilization of the protein's structure.

A question often raised in EF-related applications is the possible occurrence of electrochemical reactions and their possible impacts. The precautions taken regarding the experimental apparatus and procedure, described in Materials and Methods, along with the linearity observed on the EF strength effects (see the Fig. 2D) makes it reasonable to assume that if other contributions (e.g. electrolysis) were present, the observed behaviour would not be linear, especially at higher EF values. 

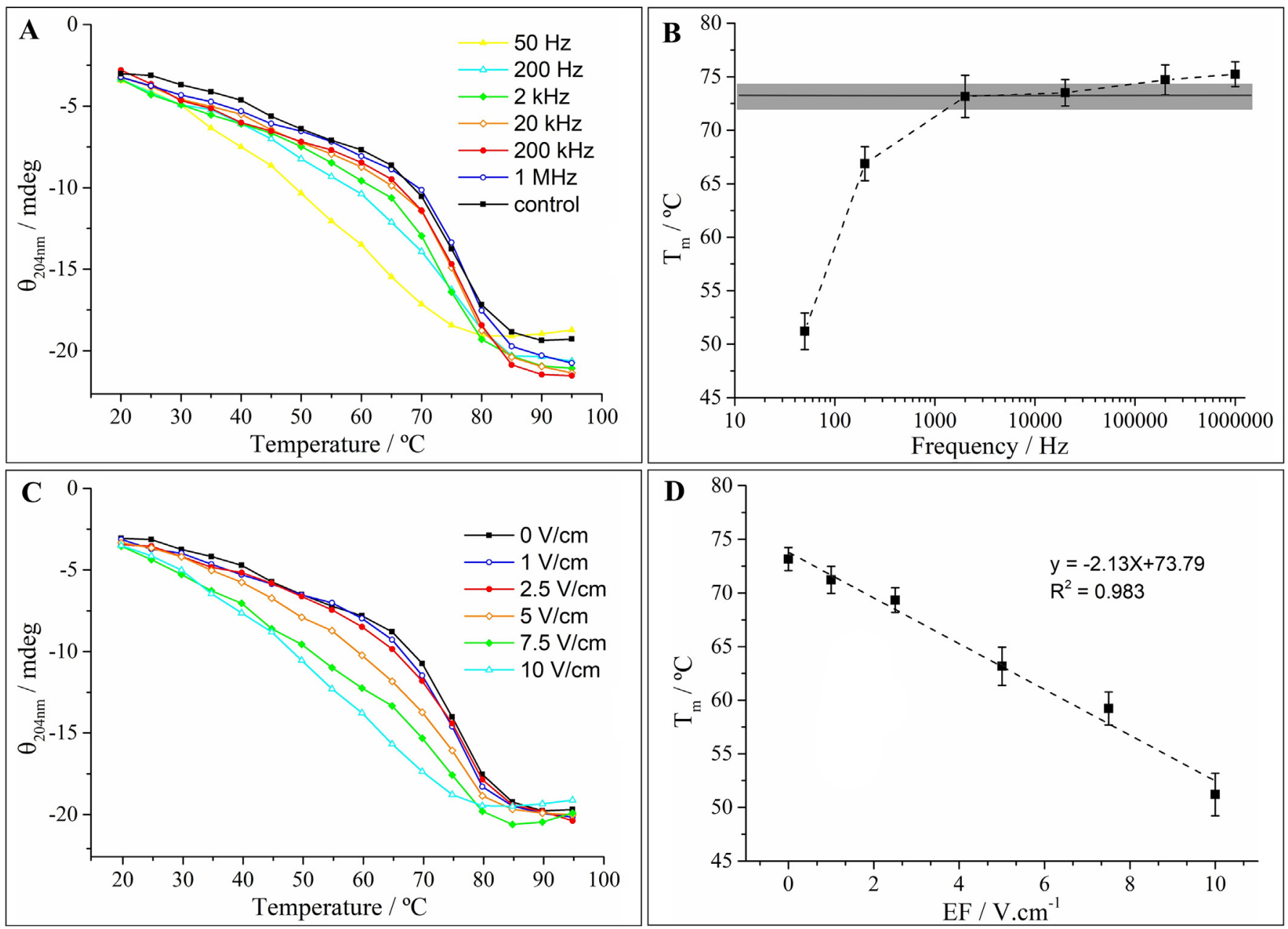

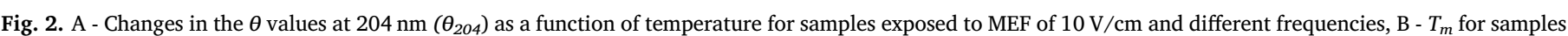

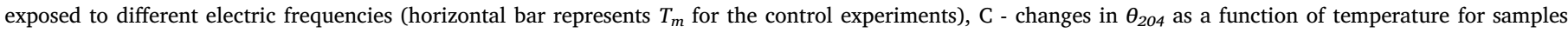
exposed to MEF at $50 \mathrm{~Hz}$ and different voltage gradients, D - $T_{m}$ for samples exposed to different EF strength at $50 \mathrm{~Hz}$.

\subsection{Effects of MEF on structural features}

Changes in $\beta$-lg structural features upon EF effects have been revealed by PEF treatments (at different EF magnitudes, exposure time and without synergy with temperature), exhibiting increased Trp exposure, increased ANS binding, secondary structure changes and differences in immunoglobulins binding (Xiang et al., 2011; Yang et al., 2018). After establishing the influence of EF strength and electrical frequency in the unfolding profile of $\beta$-lg and $T_{m}$, additional experiments were focused in the assessment of structural changes induced by $\mathrm{MEF}$ at representative conditions - i.e. $\mathrm{EF}$ of $10 \mathrm{~V} / \mathrm{cm}$ and frequencies of $50 \mathrm{~Hz}$ and $20 \mathrm{kHz}$, together with the control without the presence of MEF. Furthermore, considering the thermal transition profiles observed in $\mathrm{CD}$ results, it was decided to include the analysis of samples exposed to different temperatures, i.e. 50,70 and $90^{\circ} \mathrm{C}$. These temperatures are, respectively, just below the lower $T_{m}$ and the higher $T_{m}$ observed in this study and at a value where the thermal transition is complete in all of the conditions tested. In this scenario, it was possible to evaluate EF effects during and after the protein's unfolding.

The analysis of far-UV CD spectra of unfolded and refolded forms of the protein revealed different structural features, confirming that EF can change protein secondary structure under MEF. Table 1 presents the data from structural analysis of representative samples.

The temperature increase causes a significant change in the structural features of $\beta$-lg resulting in the loss of $\beta$-strand content, accompanied by the increase of turns and random coil. The control samples and the samples exposed to MEF at $20 \mathrm{kHz}$ experienced a loss of about half the $\beta$-strand content at $90^{\circ} \mathrm{C}$; however, it is important to note that this loss was higher for samples exposed to MEF. The use of MEF at $50 \mathrm{~Hz}$ led to a higher unfolding degree, resultant from a higher loss of $\beta$ strand, only maintaining approximately a third of the native content when subjected to $90^{\circ} \mathrm{C}$ treatment. The $\alpha$-helix content suffered small decreases with increasing temperature, comparable for all treatments up until $70{ }^{\circ} \mathrm{C}$. For the treatments at $90^{\circ} \mathrm{C}$, the $\alpha$-helix content returned to levels analogous to those of the native form both for the control and MEF at $20 \mathrm{kHz}$, while for MEF at $50 \mathrm{~Hz}$ treatments it continues to decrease. After cooling back to $20^{\circ} \mathrm{C}$, all samples exhibit partial refolding, mostly evident by the recovery of $\beta$-strand content and decrease of random coil. As seen in the varying frequency experiments, samples exposed to MEF at $50 \mathrm{~Hz}$ stand out, maintaining the low $\alpha$-helix content during refolding and exhibiting a substantial recovery of $\beta$-strand content. Overall, these results allow concluding that different secondary structures' distributions are imposed by the presence of MEF during $\beta-\mathrm{lg}$ thermal unfolding, as well as after a partial refolding for all the temperatures tested.

\subsection{Fluorescence determinations}

Exposure to temperatures of $50{ }^{\circ} \mathrm{C}$ resulted in a minor decrease in fluorescence when compared with the native protein, but there was no clear differentiation among different treatments (results not shown). However, for the temperatures of 70 and $90^{\circ} \mathrm{C}$ a clear difference exists 
Table 1

Secondary structure fractions of native $\beta-1 g$ and exposed in different thermoelectric conditions at temperatures of 50,70 and $90{ }^{\circ} \mathrm{C}$ and respective refolded forms.

\begin{tabular}{|c|c|c|c|c|}
\hline & $\alpha$-Helix & $\beta$-Strand & Turn & Random coil \\
\hline Native & $17.4 \pm 0.4$ & $42.6 \pm 1.0$ & $19.8 \pm 1.0$ & $20.3 \pm 0.7$ \\
\hline Control at $50^{\circ} \mathrm{C}$ & $14.9 \pm 0.7$ & $34.2 \pm 1.3$ & $24.5 \pm 1.1$ & $26.2 \pm 1.1$ \\
\hline Control at $70^{\circ} \mathrm{C}$ & $13.7 \pm 0.3$ & $31.8 \pm 0.6$ & $24.7 \pm 0.4$ & $29.7 \pm 0.5$ \\
\hline Control at $90^{\circ} \mathrm{C}$ & $17.1 \pm 0.1$ & $22.1 \pm 0.1$ & $25.7 \pm 1.1$ & $34.9 \pm 0.4$ \\
\hline Control $50^{\circ} \mathrm{C}$ refolded & $15.8 \pm 0.7$ & $41.1 \pm 0.8$ & $20.8 \pm 0.6$ & $22.4 \pm 1.0$ \\
\hline Control $70^{\circ} \mathrm{C}$ refolded & $13.7 \pm 0.4$ & $39.1 \pm 0.3$ & $22.4 \pm 0.2$ & $24.9 \pm 0.2$ \\
\hline Control $90^{\circ} \mathrm{C}$ refolded & $15.2 \pm 0.3$ & $26.9 \pm 0.4$ & $24.1 \pm 0.2$ & $33.8 \pm 0.8$ \\
\hline $\mathrm{EF} 20 \mathrm{kHz}$ at $50^{\circ} \mathrm{C}$ & $14.0 \pm 00.4$ & $34.4 \pm 0.3$ & $25.2 \pm 0.9$ & $26.5 \pm 0.1$ \\
\hline EF $20 \mathrm{kHz}$ at $70^{\circ} \mathrm{C}$ & $12.6 \pm 0.2$ & $29.6 \pm 1.2$ & $25.9 \pm 0.3$ & $31.6 \pm 1.3$ \\
\hline $\mathrm{EF} 20 \mathrm{kHz}$ at $90^{\circ} \mathrm{C}$ & $17.3 \pm 0.8$ & $19.1 \pm 0.8$ & $24.0 \pm 0.6$ & $39.2 \pm 0.5$ \\
\hline $\begin{array}{c}\mathrm{EF} 20 \mathrm{kHz} 50^{\circ} \mathrm{C} \\
\text { refolded }\end{array}$ & $11.7 \pm 1.7$ & $40.7 \pm 0.7$ & $22.2 \pm 0.5$ & $22.5 \pm 0.7$ \\
\hline $\begin{array}{c}\mathrm{EF} 20 \mathrm{kHz} 70^{\circ} \mathrm{C} \\
\text { refolded }\end{array}$ & $13.3 \pm 00.8$ & $38.2 \pm 1.5$ & $22.7 \pm 0.6$ & $26.0 \pm 0.9$ \\
\hline $\begin{array}{c}\mathrm{EF} 20 \mathrm{kHz} 90^{\circ} \mathrm{C} \\
\text { refolded }\end{array}$ & $14.8 \pm 0.4$ & $24.6 \pm 0.6$ & $25.6 \pm 0.7$ & $35.2 \pm 0.4$ \\
\hline $\mathrm{EF} 50 \mathrm{~Hz}$ at $50^{\circ} \mathrm{C}$ & $14.3 \pm 0.6$ & $27.7 \pm 2.1$ & $24.0 \pm 1.6$ & $33.9 \pm 2.3$ \\
\hline $\mathrm{EF} 50 \mathrm{~Hz}$ at $70^{\circ} \mathrm{C}$ & $13.7 \pm 0.9$ & $24.1 \pm 1.8$ & $25.0 \pm 1.2$ & $37.2 \pm 2.4$ \\
\hline $\mathrm{EF} 50 \mathrm{~Hz}$ at $90^{\circ} \mathrm{C}$ & $10.7 \pm 0.4$ & $12.4 \pm 1.4$ & $30.3 \pm 0.9$ & $46.0 \pm 0.8$ \\
\hline $\begin{array}{c}\mathrm{EF} 50 \mathrm{~Hz} 50^{\circ} \mathrm{C} \\
\text { refolded }\end{array}$ & $14.2 \pm 1.8$ & $39.1 \pm 1.5$ & $21.7 \pm 0.5$ & $25.6 \pm 2.3$ \\
\hline $\begin{array}{c}\mathrm{EF} 50 \mathrm{~Hz} 70^{\circ} \mathrm{C} \\
\text { refolded }\end{array}$ & $13.2 \pm 0.7$ & $27.4 \pm 0.4$ & $23.9 \pm 0.8$ & $35.5 \pm 0.5$ \\
\hline $\begin{array}{c}\mathrm{EF} 50 \mathrm{~Hz} 90^{\circ} \mathrm{C} \\
\text { refolded }\end{array}$ & $10.5 \pm 0.6$ & $23.6 \pm 0.7$ & $24.6 \pm 0.4$ & $40.9 \pm 0.8$ \\
\hline
\end{tabular}

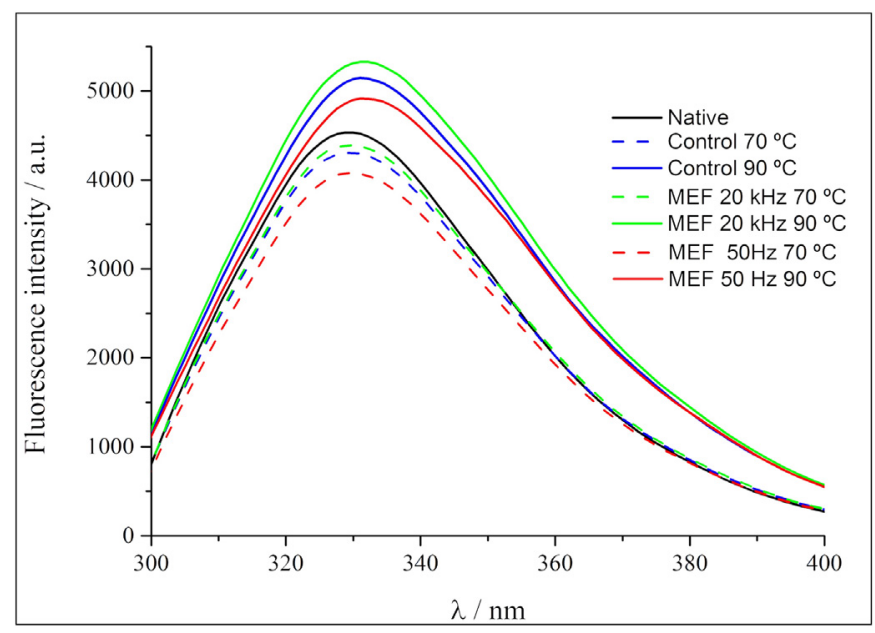

Fig. 3. Fluorescence emission spectra (excitation at $295 \mathrm{~nm}$ ) of native $\beta$-lg and exposed to temperatures of 70 and $90^{\circ} \mathrm{C}$ by control treatments (without the presence of MEF) and MEF of $10 \mathrm{~V} / \mathrm{cm}$ at $50 \mathrm{~Hz}$ and $20 \mathrm{kHz}$.

in the fluorescence measurements among the various EF conditions applied (see Fig. 3).

Exposure to temperatures of $70{ }^{\circ} \mathrm{C}$ resulted in a decrease in $\operatorname{Trp}$ fluorescence, which was more pronounced for samples exposed to an EF of $50 \mathrm{~Hz}$. Control samples and the one exposed to MEF at $20 \mathrm{kHz}$ suffered smaller decreases and exhibited a comparable fluorescence profile, with a slightly higher intensity for the latter. No shift in the fluorescence maximum was detected, indicating no change in the Trp microenvironment, thus the decrease in fluorescence observed must be the result of an increased quenching from the neighbour amino acids due to small conformation rearrangements or higher structural dynamics (Bhattacharjee \& Das, 2000; Lakowicz, 2006). Exposure to temperatures of $90^{\circ} \mathrm{C}$ resulted in an increase of Trp fluorescence and a $4 \mathrm{~nm}$ red-shift on the fluorescence maximum with a broadening of the spectra to the right in the three conditions tested. These results corroborate the occurrence of substantial structural changes resulting in

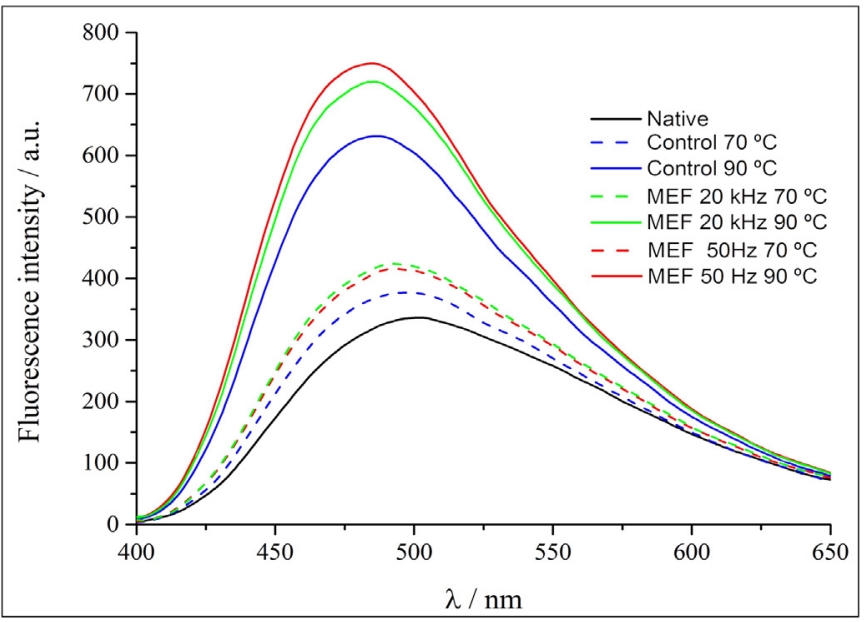

Fig. 4. ANS fluorescence emission spectra (excitation $370 \mathrm{~nm}$ ) of native $\beta-1 g$ and exposed to temperatures of 70 and $90{ }^{\circ} \mathrm{C}$ by control treatments (without the presence of MEF) and MEF of $10 \mathrm{~V} / \mathrm{cm}$ at $50 \mathrm{~Hz}$ and $20 \mathrm{kHz}$.

different Trp local environment and solvent accessibility. The presence of MEF again imposed higher fluorescence intensity for EF at $20 \mathrm{kHz}$, and lower for MEF at $50 \mathrm{~Hz}$ when compared with the control, confirming different protein conformations induced by the application of MEF at different frequencies.

The use of ANS hydrophobic fluorescent probe allows for the assessment of the degree of structural changes and possible binding affinities of proteins (Collini, D'Alfonso, \& Baldini, 2000; Hawe, Sutter, \& Jiskoot, 2008). Analogous to the Trp fluorescence results, the experiments at $50{ }^{\circ} \mathrm{C}$ did not produce significant changes in the ANS fluorescence (results not shown). The emission spectra of ANS - $\beta$-lg complex presented in Fig. 4 show a fluorescence intensity increase and a blue shift with exposure to temperatures of 70 and $90{ }^{\circ} \mathrm{C}$. The intensity increase together with the observed peak shift indicates higher energy involved in the ANS-protein interaction, therefore suggesting an increased affinity towards the hydrophobic pocket (Hawe et al., 2008). MEF-exposed samples display higher fluorescence intensities than the control, presumably resulting from an increased affinity of ANS. MEF samples at $70{ }^{\circ} \mathrm{C}$ display similar fluorescence intensities, while for $90^{\circ} \mathrm{C}$, MEF at $50 \mathrm{~Hz}$ presented higher ANS affinity than $20 \mathrm{kHz}$, both clearly above the control. The $\beta$-lg - ANS affinity for MEF treatments at $50 \mathrm{~Hz}$ and $20 \mathrm{kHz}$ is similar and clearly higher than the control. The increase in ANS florescence may arise from an increased binding affinity or from the exposure of more hydrophobic regions due higher structural changes. These variation in ANS fluorescence had few dependency of the electrical frequency used, contrast with the secondary structure distribution and Trp exposure previously observed. Instead, the presence of MEF during unfolding, regardless of the frequency applied, seems to be more relevant. These effect can be explained by an increased access to the hydrophobic barrel or an increase in the local hydrophobicity caused by MEF action, rather than the formation of new binding sites. Further studies and the use of more advanced fluorescence techniques (e.g. synchronous and 3D fluorescence) are needed to fully elucidate these phenomena and establish the origin of the ANS- $\beta$ $\lg$ fluorescence increase upon MEF treatments.

\subsection{Quenching experiments}

Binding experiments were conducted with retinol, using fluorescence quenching experiments. The fluorescence quenching data were analysed with the Stern-Volmer equation (Lakowicz, 2006) - Eq. (1):

$F_{0} / F=1+k_{q} \tau_{0}[Q]=1+K_{S V}[Q]$

The parameters $F_{O}$ and $F$ are the relative fluorescence intensities in 

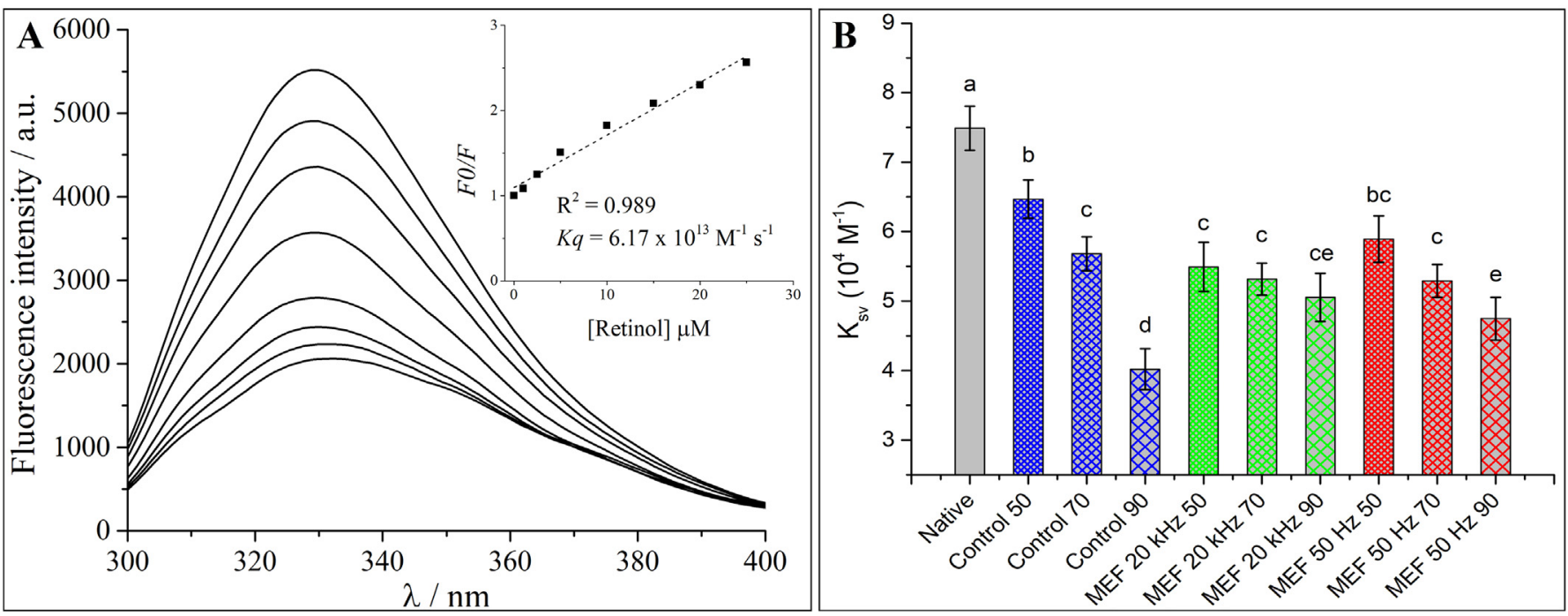

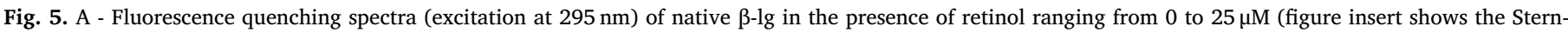
Volmer plot for binding of retinol to native $\beta-\lg$ ), B - $K_{S V}$ of Retinol binding to $\beta$-lg in native form and after exposure to different thermo-electric treatments.

the absence and presence of quencher, respectively, $K_{S V}$ is the Stern-Volmer quenching constant, $[Q]$ is the concentration of quencher, $k_{q}$ is the quenching rate constant and $\tau_{0}$ is the average lifetime of the fluorophore in the excited state, which for Trp in $\beta-\lg$ is 1.28 ns (Liang, Tajmir-Riahi, \& Subirade, 2008).

Fluorescence quenching is a process that leads to the decrease of fluorescence quantum yield from a fluorophore and it can be caused by molecular interactions involving dynamic or static mechanisms. Fig. 5A represents the fluorescent quenching caused by retinol binding to the native $\beta$-lg. Retinol- $\beta$-lg form a stable complex where a static quenching mechanism is dominant (Agudelo, Bourassa, Bariyanga, \& Tajmir-Riahi, 2017; Khorsand Ahmadi et al., 2015; Kontopidis et al., 2004).

The experimental data presents a linear Stern-Volmer relation and the estimated $k_{q}$ value is substantially higher than the maximum collisional quenching constant $\left(2.0 \times 10^{10} \mathrm{M}^{-1} \mathrm{~s}^{-1}\right)$, thus confirming the formation of a stable complex between retinol and $\beta$-lg. Once the complex formation was verified, then $K_{S V}$ can be interpreted as the association constant (Lakowicz, 2006). In order to assess the influence of the different structural features imposed by MEF on $\beta$-lg binding properties, the same procedure was reproduced with the treated samples to determine the association constant of retinol (see Fig. 5B).

$K_{S V}$ values decrease with the increasing temperature exposure, reflecting the lower accessibility of retinol to Trp in $\beta$-lg due to partial destruction of native structure. For control experiments, the decrease of $K_{S V}$ is significant for the samples exposed to the three temperature levels (i.e. $50^{\circ} \mathrm{C}, 70^{\circ} \mathrm{C}$ and $90^{\circ} \mathrm{C}$ ). Samples exposed to MEF at $50 \mathrm{~Hz}$ and $20 \mathrm{kHz}$ present no significant differences when treated at the same temperatures. $K_{S V}$ values present a higher decrease for samples exposed to $50^{\circ} \mathrm{C}$, when compared with the control (in fact, $K_{S V}$ values of MEF samples at $50{ }^{\circ} \mathrm{C}$ are comparable to those of control samples at $70{ }^{\circ} \mathrm{C}$ ). Despite the drop of $K_{S V}$ values by the exposure to higher temperatures, these values are only significant for MEF-exposed samples at $50 \mathrm{~Hz}$ and $90^{\circ} \mathrm{C}$. In general, MEF-exposed samples presented lower variation of $K_{S V}$ and retained higher affinity (in this case when exposed to higher temperatures) with retinol than the control samples.

Unlike ANS, the binding of which substantially increases with the partial unfolding of $\beta$-lg, retinol affinity suffers a decrease due to the protein's structural changes. This may be related with the nature of the interactions established between the two compounds. ANS interactions are of non-specific nature and thus ANS binds to any accessible hydrophobic patch, resultant from the unfolding process (Hawe et al., 2008). Retinol binding, however, occurs by specific interactions involving several amino acids in the interior of the $\beta$-barrel and at least one hydrogen bond (Kontopidis et al., 2002). Hence, it is expected that changes in protein conformation, particularly in the central barrel, would negatively impact the retinol- $\beta$-lg complex formation. Interestingly, and despite of the significant $(p<0.05)$ change in $K_{S V}$ values imposed by the different thermo-electric treatments, $K_{S V}$ values remain on same magnitude order demonstrating a stable complex formation. This implies the preservation of a substantial retinol affinity to the partially unfolded forms of $\beta$-lg. The secondary structure analysis has demonstrated that the refolded forms of the protein still hold substantial fractions of secondary structure, particularly $\beta$-strand content, even after sample exposure to $90{ }^{\circ} \mathrm{C}$ with or without MEF in different conditions. The preservation of significant fractions of structural features is consistent with the existence of a molten globule form and therefore the core, composed by the $\beta$-strands which form a hydrophobic cavity, may be, at least partially, preserved.

Identically to ANS experiments, samples exposed to MEF display a similar behaviour, resulting in a higher affinity of hydrophobic compounds when exposed to higher temperatures. These results reaffirm the MEF effects in $\beta$-lg interactions and the ability to form complexes with small hydrophobic compounds.

\section{Conclusion}

The presence of MEF during $\beta$-lg's thermal unfolding resulted in changes in the estimated $T_{m}$ values and in different structural features. The structural changes were observed at the target temperatures tested and upon partial refolding (after the samples have been cooled back to room temperature). The thermal transition and structural changes were largely influenced by the electrical frequency and by the electric field strength applied. The presence of MEF was also reflected in the protein's Trp fluorescence and affinity to hydrophobic compounds. Contrasting with the thermal transitions and structural features, the affinity to hydrophobic compounds appeared to have little dependence on frequency. Interestingly the effects of MEF in unfolded forms of $\beta$-lg exposed to temperatures equal or higher to $70^{\circ} \mathrm{C}$, revealed to increase the affinity to ANS and maintain higher affinity to retinol. These results demonstrated that the use MEF along with thermal unfolding gave rise to changes in structural and functional aspects of $\beta$-lg. This results in implications to the technological applications involving MEF - e.g. ohmic heating, electro filtration, dielectric separation - and it opens perspectives of new strategies to control protein functionality. 


\section{Declaration of competing interest}

The authors declare that they have no known competing financial interests or personal relationships that could have appeared to influence the work reported in this paper.

\section{Acknowledgments}

This study was supported by the Portuguese Foundation for Science and Technology (FCT) under the scope of the strategic funding of UID/ BIO/04469/2013 unit and COMPETE 2020 (POCI-01-0145-FEDER006684) and BioTecNorte operation (NORTE-01-0145-FEDER-000004) funded by European Regional Development Fund under the scope of Norte2020, Programa Operacional Regional do Norte. Rui M. Rodrigues and Ricardo N. Pereira gratefully acknowledge FCT for their financial grants with references SFRH/BD/110723/2015 and SFRH/BPD/ $81887 / 2011$, respectively. The authors would also like to acknowledge Pedro Silva for his contribution to this work.

\section{Appendix A. Supplementary data}

Supplementary data to this article can be found online at https:// doi.org/10.1016/j.foodchem.2019.125442.

\section{References}

Agudelo, D., Bourassa, P., Bariyanga, J., \& Tajmir-Riahi, H. A. (2017). Loading efficacy and binding analysis of retinoids with milk proteins: A short review. Journal of Biomolecular Structure and Dynamics, 1102, 1-9. https://doi.org/10.1080/07391102. 2017.1411833.

Bekard, I., \& Dunstan, D. E. (2014). Electric field induced changes in protein conformation. Soft Matter, 10(3), 431-437. https://doi.org/10.1039/c3sm52653d.

Bhattacharjee, C., \& Das, K. P. (2000). Thermal unfolding and refolding of $\beta$-lactoglobulin. European Journal of Biochemistry, 267(13), 3957-3964. https://doi.org/10. 1046/j.1432-1327.2000.01409.x.

Bhattacharyya, S., \& Varadarajan, R. (2013). Packing in molten globules and native states. Current Opinion in Structural Biology, 23(1), 11-21. https://doi.org/10.1016/j. sbi.2012.10.010.

Bryant, C. M., \& McClements, D. J. (1998). Molecular basis of protein functionality with special consideration of cold-set gels derived from heat-denatured whey. Trends in Food Science \& Technology, 9(4), 143-151. https://doi.org/10.1016/S0924-2244(98) 00031-4.

Cairoli, S., Iametti, S., \& Bonomi, F. (1994). Reversible and irreversible modifications of $\beta$-lactoglobulin upon exposure to heat. Journal of Protein Chemistry, 13(3), 347-354. https://doi.org/10.1007/BF01901568.

Collini, M., D'Alfonso, L., \& Baldini, G. (2000). New insight on $\beta$-lactoglobulin binding sites by 1-anilinonaphthalene-8-sulfonate fluorescence decay. Protein Science, 9(10), 1968-1974. https://doi.org/10.1110/ps.9.10.1968.

Creamer, L. K., Loveday, S. M., \& Sawyer, L. (2011). Milk proteins | $\beta$-lactoglobulin. Encyclopedia of dairy sciences (pp. 787-794). Elsevier. https://doi.org/10.1016/B9780-12-374407-4.00433-7.

English, N. J., \& Waldron, C. J. (2015). Perspectives on external electric fields in molecular simulation: Progress, prospects and challenges. Physical Chemistry Chemical Physics, 17(19), 12407-12440. https://doi.org/10.1039/c5cp00629e.

Fessas, D., Iametti, S., Schiraldi, A., \& Bonomi, F. (2001). Thermal unfolding of monomeric and dimeric $\beta$-lactoglobulins. European Journal of Biochemistry, 268(20), 5439-5448. https://doi.org/10.1046/j.0014-2956.2001.02484.x.

Geada, P., Rodrigues, R., Loureiro, L., Pereira, R., Fernandes, B., Teixeira, J. A., ... Vicente, A. A. (2018). Electrotechnologies applied to microalgal biotechnology Applications, techniques and future trends. Renewable and Sustainable Energy Reviews, 94, 656-668. https://doi.org/10.1016/j.rser.2018.06.059.

Greenfield, N. J. (2007). Using circular dichroism collected as a function of temperature to determine the thermodynamics of protein unfolding and binding interactions. Nature Protocols, 1(6), 2527-2535. https://doi.org/10.1038/nprot.2006.204.

Hawe, A., Sutter, M., \& Jiskoot, W. (2008). Extrinsic fluorescent dyes as tools for protein characterization. Pharmaceutical Research, 25(7), 1487-1499. https://doi.org/10. 1007/s11095-007-9516-9.

Iametti, S., De Gregori, B., Vecchio, G., \& Bonomi, F. (1996). Modifications occur at different structural levels during the heat denaturation of $\beta$-lactoglobulin. European Journal of Biochemistry, 237(1), 106-112. https://doi.org/10.1111/j.1432-1033. 1996.0106n.x.

Keppler, J. K., Stuhldreier, M. C., Temps, F., \& Schwarz, K. (2014). Influence of mathematical models and correction factors on binding results of polyphenols and retinol with $\beta$-lactoglobulin measured with fluorescence quenching. Food Biophysics, 9(2), 158-168. https://doi.org/10.1007/s11483-013-9328-x.

Khorsand Ahmadi, S., Mahmoodian Moghadam, M., Mokaberi, P., Reza Saberi, M., \& Chamani, J. (2015). A comparison study of the interaction between $\beta$-lactoglobulin and retinol at two different conditions: Spectroscopic and molecular modeling approaches. Journal of Biomolecular Structure and Dynamics, 33(9), 1880-1898. https://doi.org/10.1080/07391102.2014.977351.

Konrad, G., Lieske, B., \& Faber, W. (2000). A large-scale isolation of native ß-lactoglobulin: characterization of physicochemical properties and comparison with other methods. International Dairy Journal, 10(10), 713-721. https://doi.org/10.1016/ S0958-6946(00)00099-6.

Kontopidis, G., Holt, C., \& Sawyer, L. (2002). The ligand-binding site of bovine $\beta$-lactoglobulin: Evidence for a function? Journal of Molecular Biology, 318(4), 1043-1055. https://doi.org/10.1016/S0022-2836(02)00017-7.

Kontopidis, G., Holt, C., \& Sawyer, L. (2004). Invited review: $\beta$-Lactoglobulin: Binding properties, structure, and function. Journal of Dairy Science, 87(4), 785-796. https:// doi.org/10.3168/jds.S0022-0302(04)73222-1.

Lakowicz, J. R. (2006). Principles of fluorescence spectroscopy. In J. R. Lakowicz (Ed.). Principles of fluorescence spectroscopy(3rd ed.). New York, USA: Springer. https://doi. org/10.1007/978-0-387-46312-4 2006. Boston, MA: Springer US.

Liang, L., Tajmir-Riahi, H. A., \& Subirade, M. (2008). Interaction of $\beta$-lactoglobulin with resveratrol and its biological implications. Biomacromolecules, 9(1), 50-56. https:// doi.org/10.1021/bm700728k.

Loveday, S. M. (2016). $\beta$-Lactoglobulin heat denaturation: A critical assessment of kinetic modelling. International Dairy Journal, 52, 92-100. https://doi.org/10.1016/j.idairyj. 2015.08.001.

Maté, J. I., \& Krochta, J. M. (1994). ß-Lactoglobulin Separation from Whey Protein Isolate on a Large Scale. https://doi.org/10.1111/j.1365-2621.1994.tb08203.x.

Mercadante, D., Melton, L. D., Norris, G. E., Loo, T. S., Williams, M. A. K., Dobson, R. C. J., \& Jameson, G. B. (2012). Bovine $\beta$-lactoglobulin is dimeric under imitative physiological conditions: Dissociation equilibrium and rate constants over the $\mathrm{pH}$ range of 2.5-7.5. Biophysical Journal, 103(2), 303-312. https://doi.org/10.1016/j.bpj.2012. 05.041.

Nicolai, T., Britten, M., \& Schmitt, C. (2011). $\beta$-Lactoglobulin and WPI aggregates: Formation, structure and applications. Food Hydrocolloids, 25(8), 1945-1962. https://doi.org/10.1016/j.foodhyd.2011.02.006.

Orwig, S. D., \& Lieberman, R. L. (2011). Biophysical characterization of the olfactomedin domain of myocilin, an extracellular matrix protein implicated in inherited iorms of glaucoma. PLoS One, 6(1), e16347. https://doi.org/10.1371/journal.pone.0016347.

Papiz, M. Z., Sawyer, L., Eliopoulos, E. E., North, A. C. T., Findlay, J. B. C., Sivaprasadarao, R., ... Kraulis, P. J. (1986). The structure of $\beta$-lactoglobulin and its similarity to plasma retinol-binding protein. Nature, 324(6095), 383-385. https:// doi.org/10.1038/324383a0.

Pataro, G., Barca, G. M. J., Pereira, R. N., Vicente, A. A., Teixeira, J. A., \& Ferrari, G. (2014). Quantification of metal release from stainless steel electrodes during conventional and pulsed ohmic heating. Innovative Food Science and Emerging Technologies, 21, 66-73. https://doi.org/10.1016/j.ifset.2013.11.009.

Pereira, R. N., Souza, B. W. S., Cerqueira, M. A., Teixeira, J. A., \& Vicente, A. A. (2010) Effects of electric fields on protein unfolding and aggregation: Influence on edible films formation. Biomacromolecules, 11(11), 2912-2918. https://doi.org/10.1021/ bm100681a.

Pereira, R. N., Teixeira, J. A., \& Vicente, A. A. (2011). Exploring the denaturation of whey proteins upon application of moderate electric fields: A kinetic and thermodynamic study. Journal of Agricultural and Food Chemistry, 59(21), 11589-11597. https://doi. org/10.1021/jf201727s.

Perez, O. E., \& Pilosof, A. M. R. (2004). Pulsed electric fields effects on the molecular structure and gelation of $\beta$-lactoglobulin concentrate and egg white. Food Research International, 37(1), 102-110. https://doi.org/10.1016/j.foodres.2003.09.008.

Qi, X. L., Holt, C., Mcnulty, D., Clarke, D. T., Brownlow, S., \& Jones, G. R. (1997). Effect of temperature on the secondary structure of $\beta$-lactoglobulin at $\mathrm{pH}$ 6.7, as determined by CD and IR spectroscopy: A test of the molten globule hypothesis. Biochemical Journal, 324(1), 341-346. https://doi.org/10.1042/bj3240341.

Ramos, O. L., Pereira, R. N., Rodrigues, R. M., Teixeira, J. A., Vicente, A. A., \& Malcata, F. X. (2015). Whey and whey powders: Production and uses. Encyclopedia of food and healthhttps://doi.org/10.1016/B978-0-12-384947-2.00747-9.

Rieger, P. H. (1994). Electrochemistry. Dordrecht: Springer Netherlandshttps://doi.org/ 10.1007/978-94-011-0691-7.

Rocha, C. M. R., Genisheva, Z., Ferreira-Santos, P., Rodrigues, R., Vicente, A. A., Teixeira, J. A., \& Pereira, R. N. (2018). Electric field-based technologies for valorization of bioresources. Bioresource Technology, 254. https://doi.org/10.1016/j.biortech.2018. 01.068 .

Rodrigues, R. M., Martins, A. J., Ramos, O. L., Malcata, F. X., Teixeira, J. A., Vicente, A. A., \& Pereira, R. N. (2015). Influence of moderate electric fields on gelation of whey protein isolate. Food Hydrocolloids, 43, 329-339. https://doi.org/10.1016/j.foodhyd. 2014.06.002.

Rodrigues, R. M., Vicente, A. A., Petersen, S. B., \& Pereira, R. N. (2019). Electric field effects on $\beta$-lactoglobulin thermal unfolding as a function of $\mathrm{pH}$ - Impact on protein functionality. Innovative Food Science \& Emerging Technologies, 52(October 2018), 1-7. https://doi.org/10.1016/j.ifset.2018.11.010.

Samaranayake, C. P., \& Sastry, S. K. (2016a). Effect of moderate electric fi elds on inactivation kinetics of pectin methylesterase in tomatoes : The roles of electric fi eld strength and temperature. Journal of Food Engineering, 186, 17-26. https://doi.org/ 10.1016/j.jfoodeng.2016.04.006.

Samaranayake, C. P., \& Sastry, S. K. (2016b). Effects of controlled-frequency moderate electric fields on pectin methylesterase and polygalacturonase activities in tomato homogenate. Food Chemistry, 199(Supplement C), 265-272. https://doi.org/10. 1016/j.foodchem.2015.12.010.

Samaranayake, C. P., \& Sastry, S. K. (2018). LWT - food science and technology in-situ activity of $\alpha$-amylase in the presence of controlled-frequency moderate electric fi elds. LWT - Food Science and Technology, 90(October 2017), 448-454. https://doi. org/10.1016/j.lwt.2017.12.053. 
Samaranayake, C. P., Sastry, S. K., \& Zhang, H. (2005). Pulsed ohmic heating - a novel technique for minimization of electrochemical reactions during processing. Journal of Food Science, 70(8), E460-E465. https://doi.org/10.1111/j.1365-2621.2005. tb11515.x.

Sastry, S. (2008). Ohmic heating and moderate electric field processing. Food Science and Technology International, 14(5), 419-422. https://doi.org/10.1177/ 1082013208098813.

Tolkach, A., \& Kulozik, U. (2007). Reaction kinetic pathway of reversible and irreversible thermal denaturation of $\beta$-lactoglobulin. Le Lait, 87(4-5), 301-315. https://doi.org/ 10.1051/lait:2007012.

van de Weert, M. (2010). Fluorescence quenching to study protein-ligand binding: Common errors. Journal of Fluorescence, 20(2), 625-629. https://doi.org/10.1007/ s10895-011-0953-.

Wang, Q., Allen, J. C., \& Swaisgood, H. E. (1998). Protein concentration dependence of palmitate binding to $\beta$-lactoglobulin. Journal of Dairy Science, 81(1), 76-81. https://
doi.org/10.3168/jds.S0022-0302(98)75553-5.

Whitmore, L., \& Wallace, B. A. (2008). Protein secondary structure analyses from circular dichroism spectroscopy: Methods and reference databases. Biopolymers, 89(5), 392-400. https://doi.org/10.1002/bip.20853.

Xiang, B. Y., Ngadi, M. O., Ochoa-Martinez, L. A., \& Simpson, M. V. (2011). Pulsed electric field-induced structural modification of whey protein isolate. Food and Bioprocess Technology, 4(8), 1341-1348. https://doi.org/10.1007/s11947-009. 0266-z.

Yang, W., Tu, Z., Wang, H., Zhang, L., Kaltashov, I. A., Zhao, Y.,... Ye, W. (2018). The mechanism of reduced IgG/IgE-binding of $\beta$-lactoglobulin by pulsed electric field pretreatment combined with glycation revealed by ECD/FTICR-MS. Food \& Function, 9(1), 417-425. https://doi.org/10.1039/c7fo01082f.

Zhao, W., Yang, R., \& Zhang, H. Q. (2012). Recent advances in the action of pulsed electric fields on enzymes and food component proteins. Trends in Food Science \& Technology, 27(2), 83-96. https://doi.org/10.1016/j.tifs.2012.05.007. 